\title{
Desempenho produtivo e econômico de cabritos leiteiros desaleitados precocemente, criados no semiárido nordestino
}

\author{
Productive performance of dairy kids weaned early, in the semiarid created nordestino
}

\author{
PEIXOTO, Renato Mesquita ${ }^{1 *}$; VASCONCELOS, Angela Maria de ${ }^{2}$; VASCONCELOS \\ FILHO, Paulo de Tasso ${ }^{3}$; LIMA, Fátima Révia Granja ${ }^{2}$
}

\author{
${ }^{1}$ Universidade Estadual Vale do Acaraú, Programa de Pós-Graduação em Zootecnia/Embrapa Caprinos e \\ Ovinos. Sobral, Ceará, Brasil. \\ ${ }^{2}$ Universidade Estadual Vale do Acaraú, Centro de Ciências Agrárias e Biológicas, Curso de Zootecnia, \\ Sobral, Ceará, Brasil. \\ ${ }^{3}$ Universidade Estadual Vale do Acaraú, Centro de Ciências Agrárias e Biológicas, Sobral, Ceará, Brasil. \\ *Endereço para correspondência: renatomiraima@gmail.com
}

\section{RESUMO}

Objetivou-se avaliar o desempenho produtivo e a viabilidade econômica da dieta de cabritos leiteiros em diferentes períodos de desmame. Foram utilizados 24 cabritos da raça Saanen, machos e fêmeas distribuídos de acordo com os tratamentos (50, 60 e 70) dias de desmame. Os animais, ao nascer, permaneciam com as suas mães durante cinco dias para mamar o colostro e, após foi fornecido um litro de leite de cabra duas vezes ao dia até o desmame. Avaliou-se o consumo de matéria seca (MS), matéria orgânica (MO), proteína bruta $(\mathrm{PB})$, extrato etéreo (EE), fibra em detergente neutro $(\mathrm{FDN})$, peso ao nascer $(\mathrm{PN})$, peso ao desmame (PD), ganho médio diário (GMD) e ganho de peso total (GPT). O delineamento experimental foi inteiramente casualizado. Os resultados foram submetidos à análise de variância e os valores médios foram comparados pelo teste de Duncan a 5\%. Os animais desmamados aos 70 dias apresentaram maior consumo de todos os nutrientes comparados aos 50 e 60 dias. Diferiu entre todos os tratamentos o PD, GMD e GPT. Verificaram-se maiores custos com alimentação de R $\$ 900,25$ no desmame aos 70 dias, representando um acréscimo de 49,3\% e $23,8 \%$ em comparação aos cabritos desmamados aos 50 e 60 dias, respectivamente. O desmame aos 50 dias de idade resulta em menor custo de alimentação e maior incentivo à ingestão de alimentos sólidos, possibilitando ao produtor direcionar maiores quantidades de leite ao mercado.

Palavras-chave: aleitamento artificial, custo de produção, ganho de peso

\section{SUMMARY}

This study aimed to evaluate the performance and economic viability of the diet of dairy goats in different weaning periods. 24 Saanen male and female goats were distributed according to the treatments (50, 60 and 70 weaning days). Animals at birth remained with their mothers for five days to suckle colostrum, after this period, animals were given one liter goat milk twice daily until weaning. The following variables were evaluated: intake of dry matter (DM), organic matter (OM), crude protein $(\mathrm{CP})$, ether extract (EE), neutral detergent fiber (NDF) and birth weight (PD), weaning weight (PD), average daily gain (GMD) and total weight gain (GPT). The experimental design was completely randomized. The results were subjected to analysis of variance and mean values were compared by the Duncan test at 5\%. Animals weaned at 70 days of age showed higher intake of all nutrients compared with 50 and 60 days. PD, GMD GPT were different between all treatments. The highest feed cost $(\mathrm{R} \$ 900.25)$ was found when animals were weaned at 70 days of age, representing an increase of $49.3 \%$ and $23.8 \%$ compared with animals weaned at 50 and 60 days, respectively. The weaning at 50 days of age results in lower feed cost and greater incentive to eat solid food, enabling the producer to direct greater amounts of milk to the market.

Keywords: artificial feeding, production cost, weight gain 


\section{INTRODUÇÃO}

Nos últimos 15 anos, a caprinocultura demonstrou uma notória evolução, em especial nas regiões tropicais e áridas, que concentraram $74 \%$ da população mundial da espécie (RIBEIRO et al., 2007). Devendo-se isso à importância que a mesma exerce na economia e como fonte primordial de proteína animal, que atende em parte não só a necessidade nutricional da população carente das pequenas comunidades rurais nordestinas como também vem conquistando a culinária de grandes restaurantes.

Assim, na tentativa de aperfeiçoamento dos sistemas de produção e consolidação dessa atividade nas regiões brasileiras, em especial nas regiões semiáridas, buscamse introduzir técnicas inovadoras de manejo, com intuito de viabilizá-las, ao ponto de passar a ser uma importante fonte de renda. Diante disso, as explorações leiteiras tecnificadas adotam o desmame precoce e o aleitamento artificial com certa restrição de dieta líquida como práticas de manejo nas propriedades (FERREIRA et al., 2008), possibilitando destinar ao mercado quantidades maiores de leite caprino e de seus derivados.

No entanto, ao se adotar esses tipos de técnicas, torna-se fundamental estimar os custos de produção, estando a esses inseridos o custo da dieta. Nessa concepção, uma idade de desmama mais precoce promoveria redução nos custos, e consequentemente reduziria o custo de produção animal. (GONÇALVES et al., 2008).

Diversos tipos de sistema de aleitamento artificial de caprinos são mencionados na literatura, com variação apenas na quantidade, frequência, e no período de fornecimento da dieta líquida (RAMOS et al., 2004). Buscou sempre reduzir a quantidade de leite a ser fornecida aos cabritos, de forma a não prejudicar o desenvolvimento dos mesmos, obter uma maior produtividade e baratear a produção. Isto se justifica porque, durante as primeiras semanas, a base da alimentação é constituída exclusivamente por leite materno. (DUKES, 2006). Já o fornecimento da dieta sólida (concentrado + volumoso) de forma precoce aos cabritos é essencial em qualquer sistema produtivo, partindo do princípio que eles terão seu desempenho maximizado e ainda acarretará o desenvolvimento mais rápido do seu rúmen (RAMOS et al., 2004).

Nesse contexto, fazer uso de técnicas que viabilizem a produção poderá propiciar ao produtor maiores lucros em sua atividade. Portanto, este estudo foi conduzido com o objetivo de avaliar o desempenho produtivo e custo da dieta de cabritos leiteiros em diferentes períodos de desmame.

\section{MATERIAL E MÉTODOS}

O trabalho foi conduzido na Fazenda Experimental da Universidade Estadual Vale do Acaraú (FAEX), localizada a 10 quilômetros da cidade de Sobral-CE, durante o período chuvoso de janeiro a junho de 2012. O clima na região é do tipo BSH'w, segundo o sistema de Köppen, ou seja, mesotérmico com chuvas de verão e outono. Foram utilizados 24 cabritos, sendo 12 machos e 12 fêmeas da raça Saanen, distribuídos de acordo com os tratamentos (50, 60 e 70) dias de desmame na mesma proporção. $\mathrm{O}$ delineamento experimental foi inteiramente casualizado com oito cabritos por tratamento totalizando 24 animais, os quais eram pesados ao nascer e a cada sete dias até o desmame. Os resultados obtidos foram submetidos à 
Rev. Bras. Saúde Prod. Anim., Salvador, v.15, n.3, p.696-704 jul./set., 2014 http://www.rbspa.ufba.br ISSN 15199940

análise de variância pelo programa SAS ${ }^{\circledR}$ versão 9.1 (SAS INSTITUTE) e os valores médios foram comparados pelo teste de Duncan a $5 \%$ de probabilidade.

Os animais foram criados em regime intensivo, permanecendo confinados integralmente e recebendo toda a alimentação exclusivamente no cocho até à desmama. Os cabritos, ao nascer, permaneceram com suas respectivas mães durante cinco dias para mamar o colostro e após foram alocados em aprisco parcialmente coberto, com três divisórias medindo $1,25 \mathrm{~m} \times 11,40 \mathrm{~m}$ cada. A dieta líquida composta por leite de cabra foi administrada artificialmente em mamadeiras individuais em duas mamadas, sendo $500 \mathrm{~mL}$ pela manhã (8h) e a tarde (16h) logo após as ordenhas, totalizando um litro para cada animal até os 35 dias de idade. Decorrido esse tempo foram fornecidos essa mesma quantidade somente uma vez à tarde (Tabela 1) até o desmame.

Tabela 1. Sistema de aleitamento artificial da dieta líquida oferecida aos animais experimentais

\begin{tabular}{lcccc}
\hline Idade (dias) & Tipo de Aleitamento & \multicolumn{3}{c}{ Quantidade/animal/dia (L) } \\
\cline { 3 - 5 } & & Manhã & Tarde & Total \\
\hline $0-5$ & Colostro & Ad libitum & Ad libitum & - \\
$6-35$ & Leite de Cabra & 0,5 & 0,5 & 1,0 \\
$36-$ Desmame* $^{*}$ & Leite de Cabra & - & 1,0 & 1,0 \\
\hline
\end{tabular}

* Desmame 50, 60 e 70 dias de idade.

Os animais, a partir da segunda semana de vida, tiveram acesso diariamente a uma dieta total com relação volumoso: concentrado 50:50. O concentrado foi administrado $\mathrm{ad}$. libitum limitando-se o consumo até $3200 \mathrm{~g} / \mathrm{lote} / \mathrm{dia}$, sendo cada lote composto por oito animais em cada tratamento. Tanto o volumoso, feno de capim Tifton 85 (Cynodon ssp.), triturado em partículas de $3 \mathrm{~cm}$ quanto o concentrado foram fornecidos em quantidades conhecidas no cocho pela manhã, e as sobras foram previamente retiradas e pesadas em uma balança digital no dia seguinte antes do fornecimento da dieta daquele dia, como forma de medir o consumo diário por tratamento. A composição bromatológica dos componentes da dieta é exibida na Tabela 2. A água foi fornecida ad libitum em recipientes plásticos, renovada duas vezes ao dia e tiveram acesso também a sal mineral.

Tabela 2. Composição bromatológica dos componentes da dieta dos animais experimentais

\begin{tabular}{lccccc}
\hline & $\% \mathrm{MS}$ & $\% \mathrm{MO}$ & $\% \mathrm{EE}$ & $\% \mathrm{~PB}$ & $\% \mathrm{FDN}$ \\
\hline Feno & 94,85 & 87,59 & 1,21 & 7,71 & 74,80 \\
Concentrado & 92,29 & 88,21 & 5,74 & 16,40 & 21,60 \\
Dieta líquida & 12,44 & - & 26,25 & 24,68 & - \\
\hline
\end{tabular}




\section{RESULTADOS E DISCUSSÕES}

O consumo de matéria seca (CMS), matéria orgânica $(\mathrm{MO})$, proteína bruta (PB), extrato etéreo (EE) e fibra em detergente neutro (FDN) diferiram $(\mathrm{P}<0,05)$ entre os tratamentos (Tabela $3)$. Verificou-se aos 70 dias maiores médias para todos os consumos de nutrientes devido ao maior período de alimentação. É importante ressaltar que normalmente o consumo de concentrado não ocorre de maneira uniforme. Dessa maneira, acarreta em algumas situações menor consumo de concentrado por parte dos animais o que pode vir a prejudicar muitas vezes o seu desempenho produtivo e reprodutivo (MONTENEGRO et al., 1996; FERREIRA et al., 2008). O conhecimento do consumo alimentar é interessante, visto ser a medida mais associada ao desempenho animal, bem como um dos principais parâmetros a ser avaliado na formulação de dietas (YANAMOTO et al., 2007; MORENO et al., 2010).

Os valores de consumo de MS (Tabela $3)$ diferiram $(\mathrm{P}<0,05)$ entre as idades de desmame $\mathrm{e}$ foram diferentes do estabelecido pelo NRC (2007) de 300 g/animal/dia para $10 \mathrm{~kg}$ de peso, porém deve-se considerar que as exigências do NRC são estabelecidas em condições completamente adversas as nossas. Nesta pesquisa está variável foi superior aos resultados de Montenegro et al., (1998) de 11,48 a 23,71g/animal/dia ao usar diferentes proporções de soro no aleitamento de cabritos e inferiores aos de Ferreira et al., (2008) de 55,49 a 60,22g/animal/dia, adotando desmame aos 56 e 64 dias e semelhantes a Ramos et al.,(2004) de 114,9 a $350,7 \mathrm{~g} / \mathrm{animal} / \mathrm{dia}$.

Tabela 3. Consumos de matéria seca (MS), matéria orgânica (MO), proteína bruta (PB), extrato estéreo (EE) e fibra detergente neutra (FDN) da dieta dos animais experimentais

\begin{tabular}{lcccc}
\hline \multirow{2}{*}{ Variáveis } & \multicolumn{3}{c}{ Tratamentos (dias) } & \multirow{2}{*}{ CV\% } \\
\cline { 2 - 3 } & \multicolumn{3}{c}{ Consumo (g/animal/dia) } & 70 \\
\cline { 2 - 3 } & $28,27^{\mathrm{c}}$ & $57,69^{\mathrm{b}}$ & $87,94 \mathrm{a}$ & 15,14 \\
MS & $26,31^{\mathrm{c}}$ & $53,07^{\mathrm{b}}$ & $81,22 \mathrm{a}$ & 14,26 \\
MO & $3,44^{\mathrm{c}}$ & $7,32^{\mathrm{b}}$ & $11,47 \mathrm{a}$ & 16,95 \\
EE & $0,45^{\mathrm{c}}$ & $0,97^{\mathrm{b}}$ & $1,24 \mathrm{a}$ & 20,71 \\
FDN & $22,27^{\mathrm{c}}$ & $45,31^{\mathrm{b}}$ & $69,87 \mathrm{a}$ & 14,88 \\
\hline
\end{tabular}

Médias seguidas por letras distintas na mesma linha diferem entre si pelo teste de Duncan a 5\% de probabilidade. $\mathrm{T} 1=50$ dias; $\mathrm{T} 2=60$ dias; $\mathrm{T} 3=70$ dias.

O consumo médio de matéria orgânica (MO) apresentou uma relação linear crescente conforme se elevava a idade da desmama, verificando-se consumo mais elevado nos animais desmamados mais tardiamente.

$\mathrm{O}$ consumo de $\mathrm{PB}$ nesta pesquisa foi de 3,44 a $11,47 \mathrm{~g} / \mathrm{animal} / \mathrm{dia}$, inferior ao preconizado pelo National Research
Council (NRC, 2007), que recomenda para cabritos criados em confinamento um consumo de 26g/animal/dia. Atribui-se isso ao fato de que o período de aleitamento prolongado pode causar retardo na ingestão de alimentos sólidos, o que compromete o desenvolvimento dos pré-estômagos dos cabritos, acarretando redução no 
crescimento do tamanho das papilas ruminais, e isso pode exercer influência no consumo e absorção dos nutrientes (RAMOS et al., 2004). Todavia, o consumo de PB aos 60 (7,21g/animal/dia) e 70 dias $(11,47 \mathrm{~g} /$ animal/dia) encontramse similares ao relatado por Montenegro et al. (1998) de 7,80 a 9,81 g/animal/dia ao utilizarem de feno de leucena (Leucaena leucocephala) como volumoso, o qual apresenta maiores teores de proteína bruta quando comparado ao feno de capim Tífton 85 utilizado neste trabalho.

Já o consumo de EE encontra-se dentro do recomendado pela literatura
(MEDEIROS, 2007; SAEZ, 2012) de até $7 \%$ da matéria seca. Níveis superiores podem resultar em efeitos negativos que poderão afetar a atividade dos microrganismos ruminais e com isso a degradação e fermentação da fibra no rúmen. Observou-se que as atividades microbianas foram mantidas em vista do consumo de FDN de 22,27g/animal/dia, 45,31g/animal/dia e $69,87 \mathrm{~g} / \mathrm{animal} / \mathrm{dia}$ nas distintas idades de desmame $(50,60$ e 70$)$ dias, respectivamente.

Os tratamentos diferiram $(\mathrm{p}<0,05)$ para as variáveis avaliadas peso ao desmame (PD), ganho médio diário (GMD) e ganho de peso total (GPT) (Tabela 4).

Tabela 4. Peso ao nascer (PN), ao desmame (PD), ganho de peso médio diário (GPMD) e ganho de peso total (GPT) e Conversão alimentar (CA) nas diferentes idades dos animais experimentais

\begin{tabular}{lccc}
\hline \multirow{2}{*}{ Variáveis } & \multicolumn{3}{c}{ Tratamentos (dias) } \\
\cline { 2 - 4 } & 50 & 60 & 70 \\
\hline PN $(\mathrm{kg})$ & $2,98^{\mathrm{a}}$ & $3,06^{\mathrm{a}}$ & $3,22^{\mathrm{a}}$ \\
PD $(\mathrm{kg})$ & $8,43^{\mathrm{c}}$ & $10,67^{\mathrm{b}}$ & $12,64^{\mathrm{a}}$ \\
GPMD $(\mathrm{kg})$ & $0,10^{\mathrm{c}}$ & $0,12^{\mathrm{b}}$ & $0,13^{\mathrm{a}}$ \\
GPT $(\mathrm{kg})$ & $5,45^{\mathrm{c}}$ & $7,61^{\mathrm{b}}$ & $9,42^{\mathrm{a}}$ \\
CA & $2,82^{\mathrm{c}}$ & $4,80^{\mathrm{b}}$ & $6,76^{\mathrm{a}}$ \\
\hline
\end{tabular}

Médias seguidas por letras distintas na mesma linha diferem entre si pelo teste de Duncan a 5\% de probabilidade.

As médias de peso corporal ao nascer foram semelhantes, porém ao desmame diferiram entre si $(\mathrm{P}<0,05)$. Os cabritos desmamados aos 70 dias apresentaram o maior peso corporal $(12,64 \mathrm{~kg})$ podendose atribuir esse feito ao período de aleitamento mais prolongado. Esse resultado foi semelhante ao de Costa et al. (2004) de 13,0kg.

O peso médio ao desaleitamento variou de 8,43 a $12,64 \mathrm{~kg}$, o que correspondeu ao esperado e recomendado pela literatura de desmamar animais com no mínimo 2,5 vezes o peso ao nascer (FERREIRA et. al., 2008; SANCHES,
1985). Esses valores ainda foram superiores ao de Ferreira et. al. (2008) em estudo com cabritas Anglo-nubiana avaliando a idade ao desmame e a quantidade de leite, os quais observaram peso médio ao desaleitamento variando de 7,55 a $9,60 \mathrm{~kg}$ e semelhantes aos de Ramos et. al. (2004) de 10 a 14,9kg com caprinos mestiços da raça Alpina.

Entretanto, é importante salientar que na literatura diversos trabalhos já denotaram a interferência do sexo no peso ao desmame de caprinos, vindo os machos apresentarem superioridade em comparação às fêmeas (MEDEIROS et 
al., 1991; SANTOS et al., 1989; SILVA \& Araújo, 2000).

Silva \& Araújo (2000) estudando o desempenho de caprinos no semiárido nordestino relataram que os machos foram 3,0; 7,6; 5,0; e 7,0\% mais pesados que as fêmeas ao nascer, aos 28, 56 e 84 dias de idade, respectivamente. De acordo com Medeiros et al. (2005) a mediante situação se deve ao efeito anabólico da secreção de determinados hormônios sexuais que ocorre nos machos, que por consequência os possibilita absorver mais nutrientes da mãe durante a fase de desenvolvimento pré-natal.

Houve diferença $(\mathrm{P}<0,05)$ para a conversão alimentar entre os diferentes períodos de desmame, e constatou que a mesma se elevava conforme aumento da idade dos animais. Essa ocorrência deve-se ao fato deles começarem a ingerir maiores quantidades da dieta sólida, e ao maior consumo por parte dos que foram desmamados tardiamente. Situação similar ocorreu nos experimentos de Menezes, et. al., (2007) quando estes avaliavam o desempenho produtivo de caprinos de diferentes grupos raciais. Dentre os diferentes tratamentos, o desmame aos 60 dias foi o que obteve maior eficiência na taxa de conversão alimentar e ganho médio diário satisfatório, assim como o peso ao desmame dentro dos padrões encontrados na literatura.

Nesta pesquisa, o desaleitamento aos 50 e 60 dias demonstrou que se pode optar por um menor período de desmame. Não adotar um desmame precoce pode acarretar prejuízos aos produtores que deixarão de direcionar maiores quantidades de leite para a venda.

O custo com os ingredientes da dieta (Tabela 5) baseado na matéria natural aos 70 dias foram maiores ( $\mathrm{R} \$ 900,25)$, representando um acréscimo de 23,8\% em comparação aos cabritos desmamados aos 60 dias e maior $(49,3 \%)$ em relação aos 50 dias. Ressalta-se que o uso do desmame precoce aos 50 dias não interferiu no peso corporal final e que se encontra de acordo com os mencionados na literatura (COSTA et al., 2010; FERREIRA et al., 2008). Isso pode ser uma alternativa ao produtor para reduzir custos, optando por um período menor de desmame.

Tabela 5. Custos da dieta com base na matéria natural de cabritos leiteiros desmamados em diferentes idades, criados na região de Sobral - CE

\begin{tabular}{lccc}
\hline \multirow{2}{*}{ Variáveis } & \multicolumn{3}{c}{ Tratamento (dias) } \\
\cline { 2 - 4 } & 50 & 60 & 70 \\
\hline Leite de Cabra $^{1}(\mathrm{R} \$)$ & 316,46 & 383,70 & 467,64 \\
Concentrado $^{2}(\mathrm{R} \$)$ & 117,09 & 256,45 & 365,41 \\
Feno $^{3}(\mathrm{R} \$)$ & 23,20 & 45,60 & 67,20 \\
Custo Total da Dieta $(\mathrm{R} \$)_{\text {Custo/kg de ganho de peso }}^{5}$ & 456,75 & 685,75 & 900,25 \\
Custo por cabrito desmamado $^{5}$ & 6,77 & 8,03 & 8,90 \\
\hline
\end{tabular}

Os preços médios mensais dos ingredientes foram obtidos junto a distribuidores na cidade de Sobral -

Ce: ${ }^{1}$ Leite de Cabra: R \$2,00/litro (Embrapa Caprinos e Ovinos) ${ }^{3}$ Concentrado: Milho - R\$0,37/Kg, Soja

- R\$0,98/Kg, Calcário calcítico - R\$1,00/Kg, e ${ }^{3}$ Feno: $\mathrm{R} \$ 1,00 / \mathrm{Kg}$. Os custos foram calculados aplicando-se os preços vigentes no ano de $2012{ }^{4} \mathrm{Custo} / \mathrm{kg}$ de ganho de peso corporal do cabrito ao desmame (custo por cabrito desmamado/peso ao desmame); ${ }^{5}$ Custo por cabrito desmamado (custo total da dieta/número de cabritos por tratamento). Médias seguidas por letras distintas na mesma linha diferem entre si pelo teste de Ducan a 5\% de probabilidade. $\mathrm{T} 1=50$ dias; $\mathrm{T} 2=60$ dias; $\mathrm{T} 3=70$ dias. 
Observa-se, ainda na Tabela 5, que o desmame aos 70 dias resultou consequentemente em maior custo por quilograma de peso corporal $(\mathrm{R} \$ 8,90)$ em comparação a outras idades.

O custo por cabrito desmamado de $\mathrm{R} \$ 112,53$ aos 70 dias foi superior ao encontrado por Cordeiro et. al., (2007) de $\mathrm{R} \$ 104,44$ que trabalharam com leite em pó integral de vaca desmamando aos 64 dias. O desmame aos 60 dias nesta pesquisa teve um custo de $\mathrm{R} \$ 85,71$ menores que os verificados pelos mesmos autores quando utilizaram um sucedâneo lácteo (R $\$ 91,24)$.

Levando em consideração o custo do desmame aos 60 dias relatado neste trabalho e os citados na literatura quando utilizaram substitutos do leite, observou-se que, mesmo usando o leite de cabra de maior valor comercial quando comparado ao de bovino, verificou-se menor custo com a dieta. Talvez o leite caprino apresente característica nutricional superior, pois, segundo Haenlein (2004), a alta digestibilidade, alcalinidade distinta e maior capacidade tamponante são características peculiares a esse tipo de leite que possui teor elevado de ácidos graxos de cadeia curta e média, que irá favorecer o esvaziamento gástrico e, em virtude disso, reduzir o aparecimento de refluxo gastroesofágico.

Denota-se que o desmame precoce realmente acarreta uma redução de custo, porém é importante lembrar que caso não seja feito de forma eficaz poderá resultar em efeito contrário. Além disso, conforme for a finalidade e situação do empreendimento, poderá ser mais vantajoso um desmame mais tardio, haja vista que irá permitir os animais atingirem peso satisfatório para acasalamento com maior precocidade (Gonçalves et al., 2008). Simplício et al., (2000) apontam que uma nutrição adequada das crias é fator primordial para a formação de um rebanho produtivo do ponto de vista econômico, e com maior resistência a qualquer tipo de enfermidade, no que se refere à sanidade do plantel.

Conclui-se que o desmame aos 50 dias de idade resultará em um menor custo de alimentação e maior incentivo à ingestão de alimentos sólidos, possibilitando direcionar maiores quantidades de leite ao mercado. Porém, tal alternativa somente deve ser adotada se o desenvolvimento corporal dos cabritos estiver de acordo com os padrões recomendados para a raça em apreço.

\section{REFERÊNCIAS}

CORDEIRO, A.G.P.C.; UES, M.T.; FRAZÃO, A.C.N.; SILVA, M.M.C. da. Custos de alimentação para caprinos na fase de aleitamento recebendo sucedâneos com fontes de proteína láctea e de origem vegetal. In: REUNIÃO ANUAL DA SOCIEDADE BRASILEIRA DE ZOOTECNIA, 44., 2007, Jaboticabal, SP. Anais... Jaboticabal, SP: Unesp, 2007.

COSTA, R.G.; RAMOS, J.L.F.; MEDEIROS, A.N. de; BRITO, L.H.R. de. Características morfológicas e volumétricas do estômago de caprinos submetidos a diferentes períodos de aleitamento. Brazilian Journal of Veterinary Research and Animal Science, p.118-125, 2004.

COSTA, R.G.; BELTRÃO FILHO, E.M.; MEDEIROS, G.R. de; VILLARROEL, A.B.S.; CRUZ, S.E.S.B.S.; SANTOS, E.M. Substituição do leite de cabra por soro de queijo bovino para cabritos alpinos. Revista Brasileira de

Zootecnia, v.39, n.4, p.824-830, 2010. 
Rev. Bras. Saúde Prod. Anim., Salvador, v.15, n.3, p.696-704 jul./set., 2014 http://www.rbspa.ufba.br ISSN 15199940

DUCKES, H.H., Fisiologia dos

Animais Domésticos. 12.ed. Rio de Janeiro: Guanabara Koogan, 2006. 926 .

FERREIRA, M.P.B.; VILLARROEL, A.S.B.; BARROS, N.N.; FAÇANHA, D.A. Influência da idade ao desaleitamento e da quantidade de leite sobre o desempenho de cabritas da raça Anglo-nubiana. Revista de Medicina

Veterinária, v.2, n.1, p.17-23, 2008.

GONÇALVES, A.L.; LANA, R. de P.; VIEIRA, R.A.M.; HENRIQUE, D.S.; MANCIO, A.B.; PEREIRA, J.C. Avaliação de sistemas de produção de caprinos leiteiros na Região Sudeste do Brasil. Revista Brasileira de

Zootecnia, v.37, n.2, p.366-376, 2008.

HAENLEIN, G. F. W. Goat milk in human nutrition. Small Ruminant Research, v. 51, n. 1, p.155-163, 2004.

MEDEIROS, L.F.D. Avaliação de alguns caracteres reprodutivos e produtivos de caprinos da raça Anglonubiana, no Estado do Rio de Janeiro.

Arquivo da Universidade Federal Rural, v.14, n.1, p.65-82, 1991.

MEDEIROS, L.F.D. et al. Estudo do crescimento de cabritos das raças saanen, parada alemã e mestiços $1 / 2$ saanen $+1 / 2$ parda alemã. Boletim da Indústria Animal, v.62, n.1, p.55-62, 2005.

MEDEIROS, S. R. Uso de Lipídios em Dietas de Ruminantes. Informe Técnico Macal Nutrição Animal. Campo Grande, 2007.

MENEZES, J.J.L de.; GOLÇALVES, H.C.; RIBEIRO, M.S.; RODRIGUES, L.; CAÑIZARES, G.I.L.; MEDEIROS, B.B.L.; GIASSETTI, A.P. Desempenho e medidas biométricas de caprinos de diferentes grupos raciais. Revista

Brasileira de Zootecnia, v.36, n.3, p.635-642, 2007.

MONTENEGRO, M.P. Substituição do leite de vaca por soro de leite de cabra no aleitamento artificial de cabritos. 1996. 64f. Dissertação (Mestrado em Nutrição Animal) Universidade Federal do Ceará, Fortaleza.

MONTENEGRO, M. de P.; AZEVEDO, A.R. de; BARROS, N.N.; PIMENTEL, C.M.; ALVES, A.A. Uso do Soro de Queijo de Cabra no Aleitamento Artificial de Cabritos.

Revista Brasileira de Zootecnia, v.27, n.6, p.1212-1217, 1998.

MORENO, G.M.B.; SILVA

SOBRINHO, A.G.da S.; LEÃO, A.G.; LOUREIRO, C.M.B.; PEREZ, H.L.; ROSSI, R.C. Desempenho, digestibilidade e balanço de nitrogênio em cordeiros alimentados com silagem de milho ou cana-de-açúcar e dois níveis de Concentrado. Revista

Brasileira de Zootecnia, v.39, n.4, p.853-860, 2010.

NATIONAL RESEARCH COUNCIL NRC. Nutrient requirements of goats. Washington, D.C.: Nacional Academy of Science, 2007. p.271

RAMOS, J.L.F.; COSTA, R.G.; MEDEIROS, A.N. Desempenho Produtivo de Cabritos Submetidos a Diferentes Períodos de Aleitamento. Revista Brasileira de Zootecnia, v.33, n.3, p.684-690, 2004.

RIBEIRO, N.R.; ALMEIDA, M.J.O; CARVALHO, G.C.M. Melhoramento e conservação de pequenos ruminantes no Brasil. In: RIBEIRO, M. N.; CARVALHO, F. F. R. de; GOMES URVIOLA, N.; ALEJANDRO 
Rev. Bras. Saúde Prod. Anim., Salvador, v.15, n.3, p.696-704 jul./set., 2014 http://www.rbspa.ufba.br ISSN 15199940

PARIDATTI, F.; MENDOZA, B.; STEMMER, A. (Ed.). Pequenos

Ruminantes na América do Sul: Situação atual e perspectivas. Recife: EDUFRPE, 2007. 178p.

SANTOS, E.S. dos; RIBEIRO, N. M.; SANTOS, C. de L. F. Aspectos genéticos e de meio sobre os pesos prédesmama em caprinos de raças exóticas. Pesquisa Agropecuária Brasileira, v.24, n.11, p.1301-1307, 1989.

SANCHES, L.N.O. Aleitamento artificial de cabritos em crescimento. Informe Agropecuário, v.11, n.49, p.13-17, 1985.

\section{SAEZ, C.E.G. Desempenho de} cabritos alimentados com dietas contendo diferentes teores de gordura. 2012. 52 f. Dissertação (Programa de Pós-Graduação em Zootecnia) - Universidade Federal de Viçosa, Viçosa - MG, 2012.
SILVA, F.L.R. ; ARAUJO, A.M. de. Desempenho produtivo em caprinos mestiços no semi-árido do Nordeste do Brasil. Revista Brasileira de Zootecnia, v.29, n.4, p.1028-1035, 2000 .

SIMPLICIO, A.A.; SANTOS, D.O.; SALLES, H.O. Manejo de caprinos para produção de leite em regiões tropicais. Ciência Animal, v.10, n.1, p.13-27, 2000.

YAMAMOTO, S.M.; SILVA SOBRINHO, A.G.; VIDOTTI, R.M.; HOMEM JUNIOR, A.C.; PINHEIRO, R.S.B.; BUZZULINI, C. Desempenho e digestibilidade dos nutrientes em cordeiros alimentados com dietas contendo silagem de resíduos de peixe. Revista Brasileira de Zootecnia, v.36, n.4, p.1131-1139, 2007. Supl.

Data de recebimento: 03/02/2014

Data de aprovação: 23/09/2014 